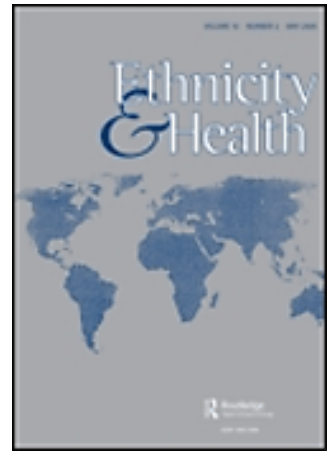

The Influence of Perceived Racial Bias and Health-related Stigma on Quality of Life Among Children with Sickle Cell Disease

\begin{tabular}{|r|l|}
\hline Journal: & Ethnicity \& Health \\
\hline Manuscript ID & CETH-2020-0098.R2 \\
\hline Manuscript Type: & Original Manuscript \\
\hline Keywords: & $\begin{array}{l}\text { stigma, racial bias, African American/Black, pediatric, health-related } \\
\text { quality of life }\end{array}$ \\
\hline \multicolumn{2}{|l}{} \\
\hline
\end{tabular}




\section{The Influence of Perceived Racial Bias and Health-related Stigma on Quality of Life Among Children with Sickle Cell Disease}

Anna M. Hood, Developmental Neurosciences, UCL Great Ormond Street Institute of Child Health, London, United Kingdom, a.hood@ucl.ac.uk (corresponding author)

Lori E. Crosby, Department of Pediatrics, University of Cincinnati College of Medicine, Cincinnati, Ohio. Division of Hematology, Cincinnati Children's Hospital Medical Center, Cincinnati, Ohio, lori.crosby@,cchmc.org

Eva Hanson, Department of Medical Sciences, University of Cincinnati College of Medicine, Cincinnati, Ohio, hansoneo@mail.uc.edu

Lisa M. Shook, Division of Hematology, Cincinnati Children's Hospital Medical Center, Cincinnati, Ohio, Lisa.Shook@cchmc.org

Jeffrey D. Lebensburger, Division of Pediatric Hematology and Oncology, University of Alabama at Birmingham, Birmingham, Alabama, jlebensburger@peds.uab.edu

Avi Madan-Swain, Division of Pediatric Hematology and Oncology, University of Alabama at Birmingham, Birmingham, Alabama, AMadan@peds.uab.edu

Megan M. Miller, Department of Psychology, Indiana University-Purdue University Indianapolis, Indianapolis, Indiana, meg.marie.miller@gmail.com

Zina Trost, Department of Physical Medicine and Rehabilitation, Virginia Commonwealth University, Richmond, Virginia, Zina.Trost@,vcuhealth.org 


\begin{abstract}
Objectives: Individuals with sickle cell disease (SCD) experience significant health problems that may result in unpredictable pain episodes and frequent healthcare utilization. Disparities in clinical care may contribute to health-related stigma and racial bias for this majority AfricanAmerican/Black population. There is less known about the influence of health-related stigma and racial bias on the health-related quality of life (HRQOL) of children with SCD. In the present study, we assessed these relationships and identified differences across demographic factors (i.e., age, gender). Design: Data was collected from African American children with SCD aged $8-16$ years (57\% male, 63\% HbSS). Children completed the Childhood Stigma Scale (adapted for SCD), the Child Perceptions of Racism in Children and Youth scale, and the Pediatric Quality of Life Inventory Sickle Cell Disease Module. Caregivers provided demographic information. Results: In the first regression model, health-related stigma $(p=.007)$ predicted HRQOL, but neither age nor gender were significant predictors. In the second regression model, age $(p=.03)$ predicted HRQOL, but neither gender nor racial bias were significant predictors. Of interest, there was a significant interaction between age, gender, and racial bias $(p=.02)$. Specifically, older girls who reported high levels of perceived racial bias had poorer HRQOL. Conclusions: Our study highlights the need for increased awareness about the effects of health-related stigma and racial bias on HRQOL for children with SCD, particularly for older girls who endorse racial bias. Our findings will guide future stigma and bias reduction interventions that may meet the needs of older girls with SCD.
\end{abstract}

Keywords: stigma; youth; pediatric; African-American/black; racial bias; health-related quality of life 


\section{Introduction}

Sickle cell disease (SCD) is a chronic, life-threatening inherited red blood cell disorder that is highly prevalent worldwide (Centers for Disease Control and Prevention, 2017). SCD principally affects populations in African countries, parts of the Middle East, and other countries near the equator. Due to increased mobility and migration, there are now approximately $20,000-$ 25,000 individuals with SCD living in Europe (Piel \& Williams, 2016). There are over 100,000 people in the United States with SCD, of whom $40 \%$ are children, and $90 \%$ are African American/Black (Hassell, 2010). Individuals with SCD experience significant health problems that may result in unpredictable pain episodes and frequent healthcare utilization (Panepinto et al., 2005; Raphael et al., 2012).

Health-related stigma refers to a form of devaluation, judgment, or social disqualification of individuals or populations who are identified with particular health-related conditions (Weiss et al., 2006). Given the myriad of complex medical and psychosocial issues associated with SCD, health-related stigma may develop and be sustained for many reasons. Individuals with SCD may feel isolated from the healthier world because physical problems limit the independent performance of daily activities, frequent SCD-related complications and resultant emergency room visits and hospitalizations may reduce social interactions with family and friends, or people may avoid including them in activities because of their illness (Al-Nasseri et al., 2019). It is possible that individuals with SCD feel they lack support from healthcare providers, at their school or workplace, or within their community (Nelson \& Hackman, 2013). Additionally, they may experience discriminatory or disrespectful behavior from others within the community or healthcare system (Van Brakel, 2006). Studies of adults with SCD have shown that higher levels of stigma are associated with more reported depressive symptoms, with adults reporting high 
levels of health-related stigma from the public, medical providers, and their families, respectively (Jenerette et al., 2012). Similarly, one study found that patients who report high levels of health-related stigma are more likely to report increased fatigue, anger, anxiety, and depression compared to patients who report lower levels of stigma. However, the patient groups in the study did not differ in terms of pain intensity (Ezenwa et al., 2016).

Studies of adolescents with SCD have found that most adolescents report moderate-tohigh levels of health-related stigma, which is negatively associated with health-related quality of life (HRQOL) measured using the SF-36 (Adeyemo et al., 2015) and the Pediatric Quality of Life Inventory (PedsQL) (Wakefield et al., 2017). Along with a lower SCD-related HRQOL, higher levels of stigma were also associated with more loneliness, higher pain interference, and less pain reduction in the hospital (Martin et al., 2018). There is less research available on stigma-reducing interventions within the adult or pediatric SCD population. However, one longitudinal study found that a pilot care-seeking intervention, focusing on educational and communication skills, increased levels of stigma for individuals with SCD (Jenerette et al., 2014). This finding outlines the complicated relationship between health-related stigma and HRQOL. Given the feelings of guilt, shame, fear, and loss of self-esteem and dignity often associated with health-related stigma (Van Brakel, 2006) and that children and adolescents generally experience low levels of HRQOL (Hood et al., 2019; Ojelabi et al., 2017), understanding the relationship between these important factors requires additional research.

Although patients and families with SCD are not monolithic, many face the additional burden of multiple environmental and SCD-related stressors with fewer personal and social resources that can act as protective factors (Smith et al., 2006). Stigmatization may exacerbate complex psychosocial and healthcare utilization issues. For example, patients with SCD 
generally live in homes with larger households (Anie et al., 2005; Yarboi et al., 2015). Further, this majority Black population experiences systemic inequities within the health care system (Nelson \& Hackman, 2013). In the emergency department, patients with SCD waited 50\% longer than patients with long bone fractures to be seen by a physician even after accounting for race and assigned triage priority (Haywood et al., 2013). Research evidence also indicates that pain complaints from patients with SCD may be treated as false or discounted by medical professionals (Jenerette, 2014). A study with a large sample assessed health care provider attitudes towards patients with SCD. They found that disease-based, rather than race-based perceived discrimination was related to increased emergency department utilization, more pain with a higher severity on good days, and more difficulty persuading their providers about pain (Haywood et al., 2014). Medical providers' mistrust of the severity of reported pain symptoms and pain treatment disparities in clinical care and emergency department visits (Haywood et al., 2009) may contribute to perceived health-related stigma among individuals with SCD.

Racial bias involves indirect and rationalized negative attitudes, rather than open bigotry and a shift in supporting cultural rather than biological justifications of the racial inferiority (McConahay, 1986). Even though there are well-documented racial disparities in general pain treatment, only a few studies have investigated perceived racial bias in patients with SCD (Green et al., 2003). On average, Black Americans are less likely to be prescribed pain medication to treat their pain and when they do receive pain medication, they are prescribed lower doses than white counterparts (Hoffman et al., 2016). Health-related stigma experiences are further complicated by racial bias experienced by the SCD population including insufficient pain medication. Youth with SCD endorse experiencing some racial bias within medical settings (Wakefield et al., 2018) and perceived racial bias is related to increased pain burden (Wakefield 
et al., 2017). In addition to stigma being related to higher pain interference, parents of patients with SCD have also reported experiencing more racial bias in the quality of care received (Burnes et al., 2008) than Black parents of children with asthma (Brousseau et al., 2009). Whether individuals appraise negative life experiences as racially biased may be shaped by various dimensions of racial identity (Sellers et al., 2003). A small mixed-methods study of adults with SCD found that racial identity was not related to disease severity or hospitalizations. However, lower public regard beliefs (e.g., how they feel others view African-Americans negatively) were associated with the participants' perspective that SCD influenced how others perceived and treated them (Royal et al., 2011).

Previous research assessing the influence of health-related stigma and racial bias on the underserved SCD population has identified challenges related to healthcare utilization, increased pain burden, and emotional distress (Bulgin et al., 2018). Most of this research, however, has focused solely on teenagers and adults, leaving these issues unexplored in younger children with $\mathrm{SCD}$. One reason may be that in the broader stigma literature (e.g., bias and explicit stereotypes), models have posited that younger children may not understand the role of stigma and bias, but it has been demonstrated that this is not always the case (Gillen-O'Neel et al., 2011). This is likely because middle childhood is a period when children develop knowledge about collective identity and self-concept (Ruble et al., 2004). In addition to age, in studies of children with SCD, the role of gender and health-related stigma and racial bias has either not been investigated (Martin et al., 2018), the study was not designed to examine this characteristic (Wakefield et al., 2018), or the study did not have adequate power to detect differences between groups (Wakefield et al., 2017). Identifying whether stigma and racial bias experiences occur in middle childhood and differs for 
boys and girls would help to guide future interventions to improve HRQOL for children with SCD.

Thus, our goal was to understand the relationship between health-related stigma and racial bias on the HRQOL in a sample of children with SCD. Additionally, we analyzed demographic factors (i.e., age, gender) that may moderate predicted relationships. We hypothesized that health-related stigma and perceived racial bias would be negatively associated with HRQOL. Further, this relationship would be moderated by age, such that older children report more health-related stigma and perceived racial bias. Based on the limited available literature, we did not have a directional hypothesis regarding gender.

\section{Materials and Methods}

\section{Procedures}

All participants or their caregivers provided informed and written consent/assent. Participants completed paper-based questionnaires in a quiet, private room at the SCD clinic. The completion of these measures took approximately 30 minutes. Caregivers provided demographic information, and medical history was obtained through a retrospective medical chart review. The institutional review board at the University of Alabama at Birmingham approved the study.

\section{Participants}

Study recruitment occurred through the SCD clinic at Children's Hospital of Alabama over six months. Patients were eligible only if followed by providers within the hematology department at the children's hospital. Inclusion criteria for the study included: 1) diagnosis of 
SCD identified through newborn screening or laboratory testing, 2) age between $8.00-16.99$ years old, 3) no known history of overt stroke, and 4) an estimated Full-Scale intelligence quotient (IQ) over 70. IQ was measured using either the Wechsler Intelligence Scale for Children (WISC-V) or the Wechsler Abbreviated Scale of Intelligence - Second Edition (WASI-II) obtained within two years of study initiation. Participants or caregivers were excluded if they were non-English speakers.

\section{Measures}

Health-related Stigma

The Childhood Stigma Scale was validated in a sample of children with epilepsy aged 9 to 14 years (Austin et al., 2004). The scale has been adapted and used previously in a sample of adolescents and young adults with SCD (Wakefield et al., 2017). Adapting the scale required minimal changes by replacing 'seizure condition' for 'SCD' on all questions. The scale is an 8item measure that assesses perceptions of stigma in children with SCD. Children rated how much of a problem an issue had been (e.g., do you feel different from other kids because you have SCD?') on a 5-point Likert scale of 'Never' to 'Very Often.' To score the scale, the items were summed and divided by the number of items. A higher score reflects greater perceptions of stigma. This scale does not have a clinical cut-off; therefore, scores above the 75th percentile were considered as high for the present study. The Cronbach's alpha for the present study is .90 indicating excellent internal consistency.

Perceived Racial Bias 
The Perceptions of Racism in Children and Youth (PRaCY) scale measured perceived racial bias and has been validated in a multicultural sample of children aged 8 to 18 years (Pachter et al., 2010). The PRaCY has been used previously in a sample of adolescents and young adults with SCD (Wakefield et al., 2017). The PRaCY is a 10 -item measure that assesses situations of racial bias that children may have experienced within their community including questions such as 'has someone made a bad or insulting remark about your race, ethnicity, or language?' Questions were rated using Yes/No responses and items were summed. A higher score reflects more perceived racial bias. This scale does not have a clinical cut-off; therefore, scores above the 75th percentile were considered as high for the present study. The Cronbach's alpha for the present study is .80 indicating good internal consistency.

\section{Health-related Quality of Life}

The Pediatric Quality of Life Inventory Sickle Cell Disease Module (PedsQL) (Panepinto et al., 2013) is a 43-item multi-dimensional rating scale with 9 subscales: pain and hurt, pain impact, pain management and control, worry (I and II), emotions, treatment, and communication (I and II) that assesses quality of life in individuals with SCD. The PedsQL has been validated in a pediatric sample of patients with SCD aged 5 to 18 years (Panepinto et al., 2013). Participants rated how much of a problem each item had been for over the past week on a 5-point scale of 'Never' to 'Almost Always.' Responses were reverse-scored and linearly transformed to a 0-100 scale $(0=100,1=75,2=50,3=25,4=0)$. Total scores were then computed as the sum of the items divided by the number of items answered. Total scores and clinical classifications (81 $100=$ high levels of HRQOL, $61-80=$ intermediate levels HRQOL, and $0-60=$ poor 
HRQOL) were used in analyses (Beverung et al., 2015). The Cronbach's alpha in this study was .95 indicating excellent internal consistency.

\section{Statistical Analyses}

All analyses were conducted using the R statistical package (R Core Team, 2017). Pearson correlations assessed relationships between age and measures of health-related stigma, perceived racial bias, and HRQOL. Genotype was initially examined as a covariate, but it did not significantly explain variance for any measure $(p>.05)$; thus, it was not included in final analyses. Two separate hierarchical linear regression models were used to determine whether demographic factors (i.e., age, gender) and health-related stigma and perceived racial bias predicted HRQOL scores for children with SCD. Effect sizes (partial eta-squared; $\eta^{2}$ ) were calculated for all effects. $\eta^{2}=.01, .06$, and .14 represented small, medium, and large effect sizes, respectively. We determined statistical significance at an alpha level of $p<.05$ two-tailed.

\section{Results}

Table 1 describes participant characteristics. Participants $(\mathrm{N}=30)$ were on average 11 years of age, all identified as African American/Black, and there were more males than females in the sample. Additionally, the majority of participants have an HbSS genotype and were receiving chronic blood transfusion at the time of the study.

[Insert Table 1 here] 
Approximately $30 \%$ of the sample reported high levels of health-related stigma and perceived racial bias (indicated by scores above the 75 th percentile). Similarly, $40 \%$ of the sample reported poor levels of HRQOL (scores <60) (see Table 2).

[Insert Table 2 here]

\section{Correlations}

Bivariate correlations indicated that younger age is significantly related to increased perceived racial bias. Older children generally reported better HRQOL, although this medium correlation did not reach statistical significance. All measures were significantly related, such that increased health-related stigma was related to increased perceived racial bias. Additionally, increased health-related stigma and perceived racial bias were related to poorer HRQOL (see Table 3).

[Insert Table 3 here]

\section{Hierarchical Linear Regressions}

We first assessed whether age, gender, and health-related stigma predicted HRQOL and demonstrated a significant overall model, $F(7,22)=4.59, p=.003, r=.46$. Specifically, healthrelated stigma predicted HRQOL, but neither age nor gender were significant predictors. The next model assessed whether age, gender, and perceived racial bias predicted HRQOL and demonstrated a significant overall model, $F(7,22)=4.59, p<.001, r=.52$. Specifically, but 
neither gender nor perceived racial bias were significant independent predictors. However, there was a significant interaction between age and perceived racial bias (see Table 4).

[Insert Table 4 here]

Of interest, there was a 3-way interaction among age, gender, and perceived racial bias, which indicated that boys generally had higher HRQOL that did not differ as a function of racial bias or age. In contrast, girls who reported high levels of racial bias had HRQOL that differed as a function of age. Specifically, older girls with high levels of perceived racial bias reported poorer HRQOL (see Figure 1).

[Insert Figure 1 here]

\section{Discussion}

Health-related stigma is a major social determinant of health that drives morbidity, mortality, and health disparities and has increasingly become a public health concern that requires more attention to understand its causes (Hatzenbuehler et al., 2013). Although there is less research into the role of perceived racial bias and its impact on health and psychosocial functioning (Priest \& Williams, 2018), the existing evidence indicates that, for pediatric patients, experiencing racial bias severely impacts their lives and health outcomes. For instance, patients may not follow physician recommendations because of mistrust for a majority-white healthcare system (Carter et al., 2017). Only recently has the negative impact of these factors been investigated in SCD samples (Bulgin et al., 2018; Martin et al., 2018). 
Similar to previous research (Martin et al., 2018; Wakefield et al., 2017), the current study found that children with SCD reported high levels of health-related stigma and perceived racial bias in their daily lives and that this predicted poorer HRQOL. Novel findings were an interaction among age, gender, and perceived racial bias. Specifically, older girls with higher levels of perceived racial bias reported poorer HRQOL. Our study highlights the need for increased awareness about the effects of health-related stigma and racial bias in children with SCD and demonstrates that older girls seem particularly affected by racial bias, which negatively impacts their HRQOL.

The moderate positive relationship found between health-related stigma and perceived racial bias highlights that they are overlapping processes rooted in larger systems of inequality (Hatzenbuehler et al., 2013). However, stigmatization for patients with SCD is also distinct from racial bias in specific ways. Patients with SCD have previously reported experiencing stigma related to disease-related factors including, pain episodes that require management with opioids, emergency department visits and hospitalizations, and delayed growth and puberty (Bulgin et al., 2018). Other aspects of living with SCD that may also be stigmatizing are cognitive challenges, educational difficulties, and school absences (Jenerette \& Brewer, 2010). Additionally, children with SCD may overhear pejorative terms used by medical providers such as 'sicklers,' 'frequent flyers,' or 'clock watchers' when they seek treatment for pain (Glassberg et al., 2013). The lack of relationship between age and health-related stigma $(r=-.02)$ is also telling. This finding indicates that the generally high levels of health-related stigma reported did not differ between younger and older children with SCD suggesting that stigma is perceived from a very young age, which is similar to previous work assessing ethnicity-related stigma in young children (Gillen-O’Neel et al., 2011). 
For the older girls in the present study, high levels of perceived racial bias had a strong negative influence on their HRQOL indicating that feelings of racial bias may be compounded for girls with SCD. Specifically, black girls are often forced to deal with harmful perceptions that they are more mature and less in need of protection (Epstein et al., 2017). These negative stereotypes, such as not being 'feminine' or 'ladylike,' may make them feel that they are being held to a different standard compared to their white counterparts. Additionally, the intersectionality of being black and female may also lead to experiencing specific forms of racial bias that black males may not experience (Cooper, 2016).

Improving health care equity and reducing delays in health services are large-scale changes that may ultimately reduce perceived racial bias for children with SCD (Lee et al., 2019). Community health workers, who receive specialist training in treating patients with SCD, can be a source of social support and can aid in navigating complex healthcare systems (Hsu et al., 2016). Medical providers can also take action by improving their cultural competence and learning how to communicate with children with SCD effectively. A cross-cultural care training curriculum for pediatric hematology/oncology fellows demonstrated enhanced communication skills and improved delivery of cross-cultural care using self-reflection, small-group role-play, and interactive sessions with language interpreters (Rao et al., 2017).

Other methods to reduce health-related stigma and racial bias could include improving patient-provider interactions. Negative healthcare experiences may exacerbate existing feelings of stigma and bias, whilst impeding the self-management of SCD symptoms (Wakefield et al., 2017). Previous research in non-SCD populations has demonstrated that workshops for medical providers with involvement from advocacy groups that enhance knowledge, attitudes, skills, and shared communication between patients and doctors, are successful community and hospital- 
level stigma reduction strategies (Heijnders \& Van Der Meij, 2006). In studies of adults with SCD, improving provider communication has been shown to improve patient trust (Haywood et al., 2010) and a short video intervention highlighting the challenges experienced when seeking treatment for pain in emergency departments or upon admittance to the hospital reduces clinician negative attitudes towards adult patients with SCD (Haywood et al., 2011).

There are limitations to the present study. Due to our sample size, we did not have the power to detect small effects. Replication with a larger sample size may detect an interaction among health-related stigma and demographic factors. We also used self-report methods instead of interviews. Qualitative information from participants would have allowed us to explore the emotions participants experience related to health-related stigma and racial bias (Wakefield et al., 2018). Caregivers could be in the same room when children completed measures. It is possible that the child's response was influenced by the presence of their caregiver. Many participants in our sample were receiving chronic transfusion therapy and reported poor-tomoderate HRQOL. Previous research has demonstrated that children in this treatment group report poorer HRQOL than other children with SCD (Hood et al., 2019). We may have obtained different results in a group of patients with less disease severity and fewer hospital contacts (e.g., all participants treated with hydroxyurea). Finally, we included pediatric patients at a single center in a southern state in the United States. This limits the generalizability of our findings as they may not be representative of patients in different states or countries.

Despite these limitations, our study highlights the need for increased awareness about the effects of health-related stigma and racial bias in children with SCD. We demonstrated that older girls with SCD were particularly affected by perceived racial bias and that this contributes to their quality of life HRQOL. This sub-population may be at particular risk for experiencing poor 
HRQOL in response to racial bias and may benefit from additional support and developing shared communication skills with the clinical team. Determining ways to improve doctor-patient communication could contribute to a better long-term patient-provider relationship, which could serve as a protective factor. Other opportunities for future research stemming from our findings include examining the effect of providing patients with opportunities to share their stigmatizing experiences openly and for medical providers to learn bias-reduction skills/strategies. 


\section{Funding}

Anna Hood was supported by the National Heart, Lung, and Blood Institute under Grant (1F32HL143915).

\section{Acknowledgements}

The authors would like to thank the patients and the medical providers at Children's Hospital of Alabama for their cooperation in generating the data needed for this study.

\section{Declaration of Interest Statement}

No potential conflict of interest was reported by the authors.

\section{Data Availability Statement}

The data that support the findings of this study are available from the last author, [ZT], upon reasonable request (zina.trost@vcuhealth.org). 


\section{References}

Adeyemo, T. A., Ojewunmi, O. O., Diaku-Akinwumi, I. N., Ayinde, O. C., \& Akanmu, A. S. (2015). Health related quality of life and perception of stigmatisation in adolescents living with sickle cell disease in Nigeria: A cross sectional study. Pediatric Blood \& Cancer, $62(7), 1245-1251$.

Al-Nasseri, K., Joseph, J., Al Nasiri, Y., Al Mawali, A., \& Jacob, E. (2019). Do young Omani adults with sickle cell disease experience stigma from having the disease? Iraq Medical Journal, 3(3).

Anie, K. A., Telfair, J., \& Group, S. C. D. T. S. (2005). Multi-site study of transition in adolescents with sickle cell disease in the United Kingdom and the United States. De Gruyter.

Austin, J. K., MacLeod, J., Dunn, D. W., Shen, J., \& Perkins, S. M. (2004). Measuring stigma in children with epilepsy and their parents: instrument development and testing. Epilepsy \& Behavior, 5(4), 472-482.

Beverung, L. M., Varni, J. W., \& Panepinto, J. A. (2015). Clinically meaningful interpretation of pediatric health-related quality of life in sickle cell disease. Journal of Pediatric Hematology/Oncology, 37(2), 128.

Brousseau, D. C., Mukonje, T., Brandow, A. M., Nimmer, M., \& Panepinto, J. A. (2009). Dissatisfaction with hospital care for children with sickle cell disease not due only to race and chronic disease. Pediatric Blood \& Cancer, 53(2), 174-178.

Bulgin, D., Tanabe, P., \& Jenerette, C. (2018). Stigma of Sickle Cell Disease: A Systematic Review. Issues in Mental Health Nursing, 39(8), 675-686.

Burnes, D. P. R., Antle, B. J., Williams, C. C., \& Cook, L. (2008). Mothers raising children with 
sickle cell disease at the intersection of race, gender, and illness stigma. Health \& Social Work, 33(3), 211-220.

Carter, R. T., Lau, M. Y., Johnson, V., \& Kirkinis, K. (2017). Racial discrimination and health outcomes among racial/ethnic minorities: A meta-analytic review. Journal of Multicultural Counseling and Development, 45(4), 232-259.

Centers for Disease Control and Prevention. (2017). Data \& Statistics on Sickle Cell Disease. Centers for Disease Control and Prevention. https://www.cdc.gov/ncbddd/sicklecell/data.html

Cooper, B. (2016). Intersectionality. In The Oxford handbook of feminist theory.

Epstein, R., Blake, J., \& González, T. (2017). Girlhood interrupted: The erasure of Black girls' childhood. Available at SSRN 3000695.

Ezenwa, M., Yao, Y., Molokie, R., Wang, Z., Suarez, M., Zhao, Z., Carrasco, J., Angulo, V., Shuey, D., \& Roach, K. (2016). (157) The association of sickle cell-related stigma with physical and emotional symptoms in patients with sickle cell pain. The Journal of Pain, 17(4), S15.

Gillen-O’Neel, C., Ruble, D. N., \& Fuligni, A. J. (2011). Ethnic stigma, academic anxiety, and intrinsic motivation in middle childhood. Child Development, 82(5), 1470-1485.

Glassberg, J. A., Tanabe, P., Richardson, L., \& DeBaun, M. (2013). Among emergency physicians, use of the term "Sickler" is associated with negative attitudes toward people with sickle cell disease. American Journal of Hematology, 88(6), 532-533.

Green, C. R., Anderson, K. O., Baker, T. A., Campbell, L. C., Decker, S., Fillingim, R. B., Kaloukalani, D. A., Lasch, K. E., Myers, C., \& Tait, R. C. (2003). The unequal burden of pain: confronting racial and ethnic disparities in pain. Pain Medicine, 4(3), 277-294. 
Hassell, K. L. (2010). Population Estimates of Sickle Cell Disease in the U.S. American Journal of Preventive Medicine, 38(4, Supplement), S512-S521. https://doi.org/http://dx.doi.org/10.1016/j.amepre.2009.12.022

Hatzenbuehler, M. L., Phelan, J. C., \& Link, B. G. (2013). Stigma as a fundamental cause of population health inequalities. American Journal of Public Health, 103(5), 813-821.

Haywood, C., Lanzkron, S., Hughes, M. T., Brown, R., Massa, M., Ratanawongsa, N., \& Beach, M. C. (2011). A video-intervention to improve clinician attitudes toward patients with sickle cell disease: the results of a randomized experiment. Journal of General Internal Medicine, 26(5), 518-523.

Haywood, C., Lanzkron, S., Ratanawongsa, N., Bediako, S. M., Lattimer, L., Powe, N. R., \& Beach, M. C. (2010). The association of provider communication with trust among adults with sickle cell disease. Journal of General Internal Medicine, 25(6), 543-548.

Haywood, C., Beach, M. C., Lanzkron, S., Strouse, J. J., Wilson, R., Park, H., Witkop, C., Bass, E. B., \& Segal, J. B. (2009). A systematic review of barriers and interventions to improve appropriate use of therapies for sickle cell disease. Journal of the National Medical Association, 101(10), 1022-1033.

Haywood, C., Diener-West, M., Strouse, J., Carroll, C. P., Bediako, S., Lanzkron, S., Haythornthwaite, J., Onojobi, G., Beach, M. C., \& Woodson, T. (2014). Perceived discrimination in health care is associated with a greater burden of pain in sickle cell disease. Journal of Pain and Symptom Management, 48(5), 934-943.

Haywood, C., Tanabe, P., Naik, R., Beach, M. C., \& Lanzkron, S. (2013). The impact of race and disease on sickle cell patient wait times in the emergency department. The American Journal of Emergency Medicine, 31(4), 651-656. 
Heijnders, M., \& Van Der Meij, S. (2006). The fight against stigma: an overview of stigmareduction strategies and interventions. Psychology, Health \& Medicine, 11(3), 353-363.

Hoffman, K. M., Trawalter, S., Axt, J. R., \& Oliver, M. N. (2016). Racial bias in pain assessment and treatment recommendations, and false beliefs about biological differences between blacks and whites. Proceedings of the National Academy of Sciences, 113(16), 4296-4301.

Hood, A. M., Reife, I., King, A. A., \& White, D. A. (2019). Brief Screening Measures Identify Risk for Psychological Difficulties Among Children with Sickle Cell Disease. Journal of Clinical Psychology in Medical Settings, 1-11.

Hsu, L. L., Green, N. S., Ivy, E. D., Neunert, C. E., Smaldone, A., Johnson, S., Castillo, S., Castillo, A., Thompson, T., \& Hampton, K. (2016). Community health workers as support for sickle cell care. American Journal of Preventive Medicine, 51(1), S87-S98.

Jenerette, C. M., A. Brewer, C., Crandell, J., \& I. Ataga, K. (2012). Preliminary validity and reliability of the sickle cell disease health-related stigma scale. Issues in Mental Health Nursing, 33(6), 363-369.

Jenerette, C. M., \& Brewer, C. (2010). Health-related stigma in young adults with sickle cell disease. Journal of the National Medical Association, 102(11), 1050.

Jenerette, C. M., Brewer, C. A., Edwards, L. J., Mishel, M. H., \& Gil, K. M. (2014). An intervention to decrease stigma in young adults with sickle cell disease. Western Journal of Nursing Research, 36(5), 599-619.

Lee, L., Smith-Whitley, K., Banks, S., \& Puckrein, G. (2019). Reducing Health Care Disparities in Sickle Cell Disease: A Review. Public Health Reports, 0033354919881438.

Martin, S. R., Cohen, L. L., Mougianis, I., Griffin, A., Sil, S., \& Dampier, C. (2018). Stigma and pain in adolescents hospitalized for sickle cell vasoocclusive pain episodes. The Clinical 
Journal of Pain, 34(5), 438-444.

McConahay, J. B. (1986). Modern racism, ambivalence, and the modern racism scale.

Nelson, S. C., \& Hackman, H. W. (2013). Race matters: Perceptions of race and racism in a sickle cell center. Pediatric Blood \& Cancer, 60(3), 451-454.

Ojelabi, A., Graham, Y., \& Ling, J. (2017). Health-related Quality of Life Predictors in Children and Adolescents with Sickle Cell Disease: A Systematic Review. International Journal of TROPICAL DISEASE \& Health, 22(2), 1-14. https://doi.org/10.9734/IJTDH/2017/31954

Pachter, L. M., Szalacha, L. A., Bernstein, B. A., \& García Coll, C. (2010). Perceptions of Racism in Children and Youth (PRaCY): Properties of a self-report instrument for research on children's health and development. Ethnicity \& Health, 15(1), 33-46.

Panepinto, J. A., Brousseau, D. C., Hillery, C. A., \& Scott, J. P. (2005). Variation in hospitalizations and hospital length of stay in children with vaso-occlusive crises in sickle cell disease. Pediatric Blood \& Cancer, 44(2), 182-186.

Panepinto, J. A., Torres, S., Bendo, C. B., McCavit, T. L., Dinu, B., Sherman-Bien, S., Bemrich-Stolz, C., \& Varni, J. W. (2013). PedsQL ${ }^{\mathrm{TM}}$ sickle cell disease module: feasibility, reliability, and validity. Pediatric Blood \& Cancer, 60(8), 1338-1344.

Piel, F. B., \& Williams, T. N. (2016). Sickle cell anemia: history and epidemiology. In Sickle Cell Anemia (pp. 23-47). Springer.

Priest, N., \& Williams, D. R. (2018). Racial discrimination and racial disparities in health.

R Core Team. (2017). R: A language and environment for statistical computing. R Foundation for Statistical Computing.

Rao, A. N., Warad, D., \& Rodriguez, V. (2017). Cross-cultural care training for pediatric hematology/oncology fellows. MedEdPORTAL: The Journal of Teaching and Learning 
Resources, 13.

Raphael, J. L., Mei, M., Mueller, B. U., \& Giordano, T. (2012). High resource hospitalizations among children with vaso-occlusive crises in sickle cell disease. Pediatric Blood \& Cancer, $58(4), 584-590$.

Royal, C. D., Jonassaint, C. R., Jonassaint, J. C., \& De Castro, L. M. (2011). Living with sickle cell disease: traversing 'race'and identity. Ethnicity \& Health, 16(4-5), 389-404.

Ruble, D. N., Alvarez, J., Bachman, M., \& Cameron, J. (2004). The development of a sense of "we": The emergence and implications of children's collective identity. In The development of the social self (pp. 43-90). Psychology Press.

Sellers, R. M., Caldwell, C. H., Schmeelk-Cone, K. H., \& Zimmerman, M. A. (2003). Racial identity, racial discrimination, perceived stress, and psychological distress among African American young adults. Journal of Health and Social Behavior, 302-317.

Smith, L. A., Oyeku, S. O., Homer, C., \& Zuckerman, B. (2006). Sickle cell disease: a question of equity and quality. Pediatrics, 117(5), 1763-1770.

Van Brakel, W. H. (2006). Measuring health-related stigma - a literature review. Psychology, Health \& Medicine, 11(3), 307-334.

Wakefield, E. O., Pantaleao, A., Popp, J. M., Dale, L. P., Santanelli, J. P., Litt, M. D., \& Zempsky, W. T. (2018). Describing Perceived Racial Bias Among Youth With Sickle Cell Disease. Journal of Pediatric Psychology.

Wakefield, E. O., Popp, J. M., Dale, L. P., Santanelli, J. P., Pantaleao, A., \& Zempsky, W. T. (2017). Perceived racial bias and health-related stigma among youth with sickle cell disease. Journal of Developmental \& Behavioral Pediatrics, 38(2), 129-134.

Weiss, M. G., Ramakrishna, J., \& Somma, D. (2006). Health-Related Stigma: Rethinking 
Concepts and Interventions. Psychology, Health, and Medicine, 11(3), 277 to 287. https://doi.org/10.1080/13548500600595053

Yarboi, J., Compas, B. E., Brody, G. H., White, D., Rees Patterson, J., Ziara, K., \& King, A. (2015). Association of social-environmental factors with cognitive function in children with sickle cell disease. Child Neuropsychology, 1-18. 
Table 1. Characteristics of Participants

\begin{tabular}{|c|c|}
\hline & Children with SCD \\
\hline \multicolumn{2}{|l|}{ Mean (SD) } \\
\hline Age (years) & $11.3(2.7)$ \\
\hline Range & $8-16$ \\
\hline \multicolumn{2}{|l|}{$\mathrm{N}(\%)$} \\
\hline \multicolumn{2}{|l|}{ Gender } \\
\hline Female & $13(43)$ \\
\hline Male & $17(57)$ \\
\hline \multicolumn{2}{|l|}{ Race/ethnicity } \\
\hline African American/Black & $30(100)$ \\
\hline \multicolumn{2}{|l|}{ SCD genotype } \\
\hline $\mathrm{HbSS}$ & $19(63)$ \\
\hline $\mathrm{HbSC}$ & $7(23)$ \\
\hline $\mathrm{HbS} \beta+$ thalassemia & $3(10)$ \\
\hline Not reported & $1(3)$ \\
\hline \multicolumn{2}{|l|}{ Treatment type } \\
\hline Chronic blood transfusion/Pheresis & $19(63)$ \\
\hline Hydroxyurea & $8(27)$ \\
\hline Not reported & $3(10)$ \\
\hline \multicolumn{2}{|l|}{ Caregiver education } \\
\hline No high school degree & $2(6)$ \\
\hline High school graduate or GED & $6(20)$ \\
\hline Some college, no degree & $6(20)$ \\
\hline Occupational/technical/vocational program & $3(10)$ \\
\hline Associate degree & $5(17)$ \\
\hline Bachelor's degree & $6(20)$ \\
\hline Master's degree & $2(7)$ \\
\hline
\end{tabular}


Table 2. Participant scores on measures of health-related stigma, perceived racism, and quality of life

\begin{tabular}{lc}
\hline \multicolumn{1}{c}{ Measures } & Children with SCD \\
\hline Childhood Stigma Scale & $2.2(1.2)$ \\
Mean (SD) & $1-5$ \\
Range & $10(30 \%)$ \\
Scores above 75th percentile & \\
& \\
PRaCY & $3.6(2.7)$ \\
Mean (SD) & $1-9$ \\
Range & $8(27 \%)$ \\
Scores above 75th percentile & \\
& \\
PedsQL & $64.0(20.9)$ \\
Mean (SD) & $24-99$ \\
Range & $12(40 \%)$ \\
Scores in the poor range & \\
Note: Higher scores on the Childhood Stigma Scale and PRaCY reflect more \\
perceived health-related stigma and racial bias, respectively. Lower scores on \\
the PedsQL reflect poorer quality of life. SCD = Sickle Cell Disease; SD = \\
$\begin{array}{l}\text { Standard Deviation; PRaCY = Perceptions of Racism in Children and Youth; } \\
\text { PedsQL = Pediatric Quality of Life Inventory Sickle Cell Disease Module }\end{array}$
\end{tabular}


Table 3. Correlations among age and measures of health-related stigma, perceived racial bias, and quality of life

\begin{tabular}{|c|c|c|c|}
\hline Variable & 1 & 2 & 3 \\
\hline 1. Age & & & \\
\hline 2. Childhood Stigma Scale & $\begin{array}{c}-.02 \\
{[-.38, .34]}\end{array}$ & & \\
\hline 3. PRACY & $\begin{array}{c}-.47 * * \\
{[-.71,-.13]}\end{array}$ & $\begin{array}{l}.39^{*} \\
{[.04, .66]}\end{array}$ & \\
\hline 4. PEDSQL & $\begin{array}{c}.27 \\
{[-.10, .57]}\end{array}$ & $\begin{array}{l}-.60 * * \\
{[-.79,-.31]}\end{array}$ & $\begin{array}{l}-.40^{*} \\
{[-.67,-.05]}\end{array}$ \\
\hline
\end{tabular}




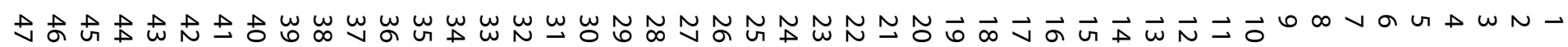

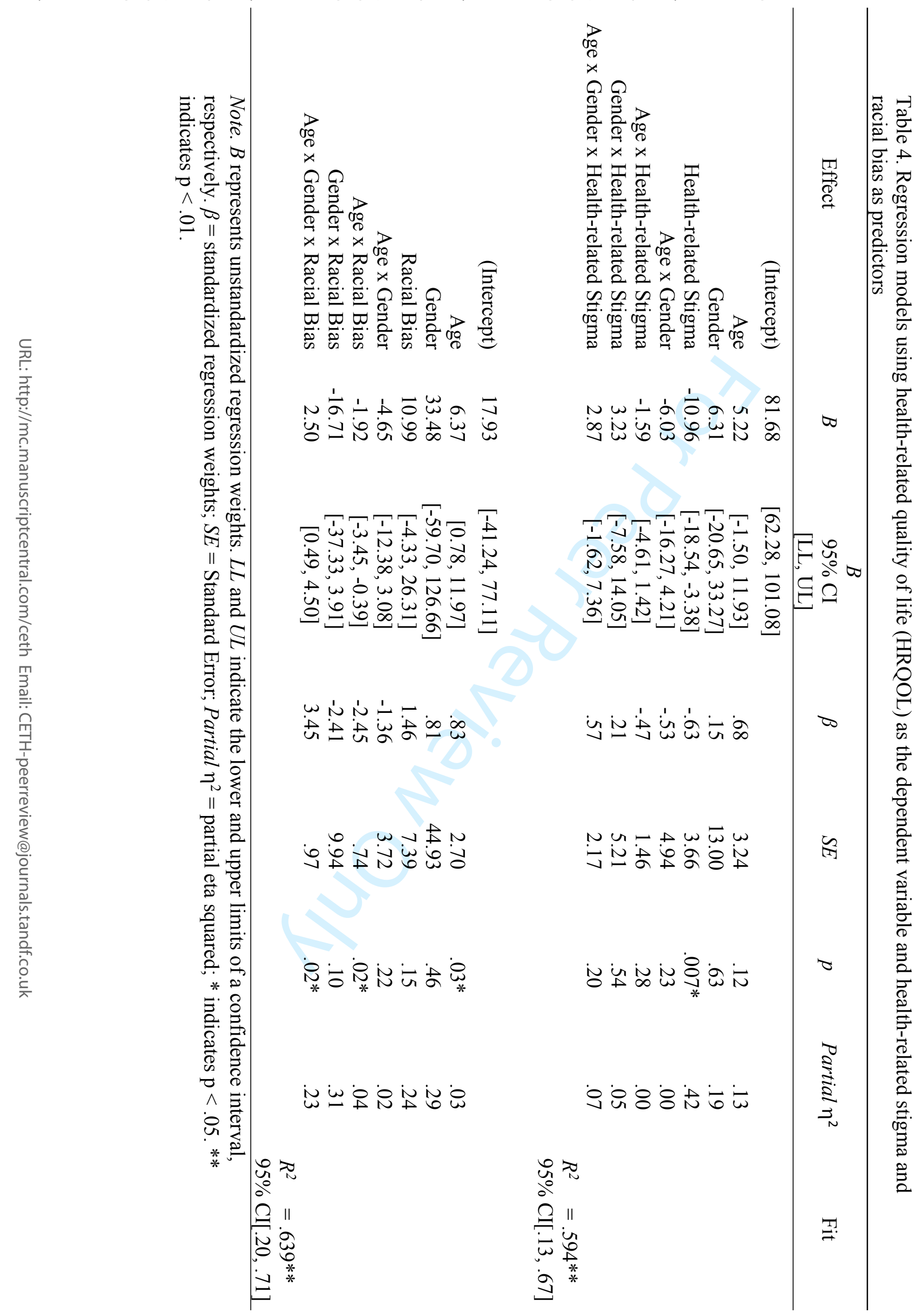




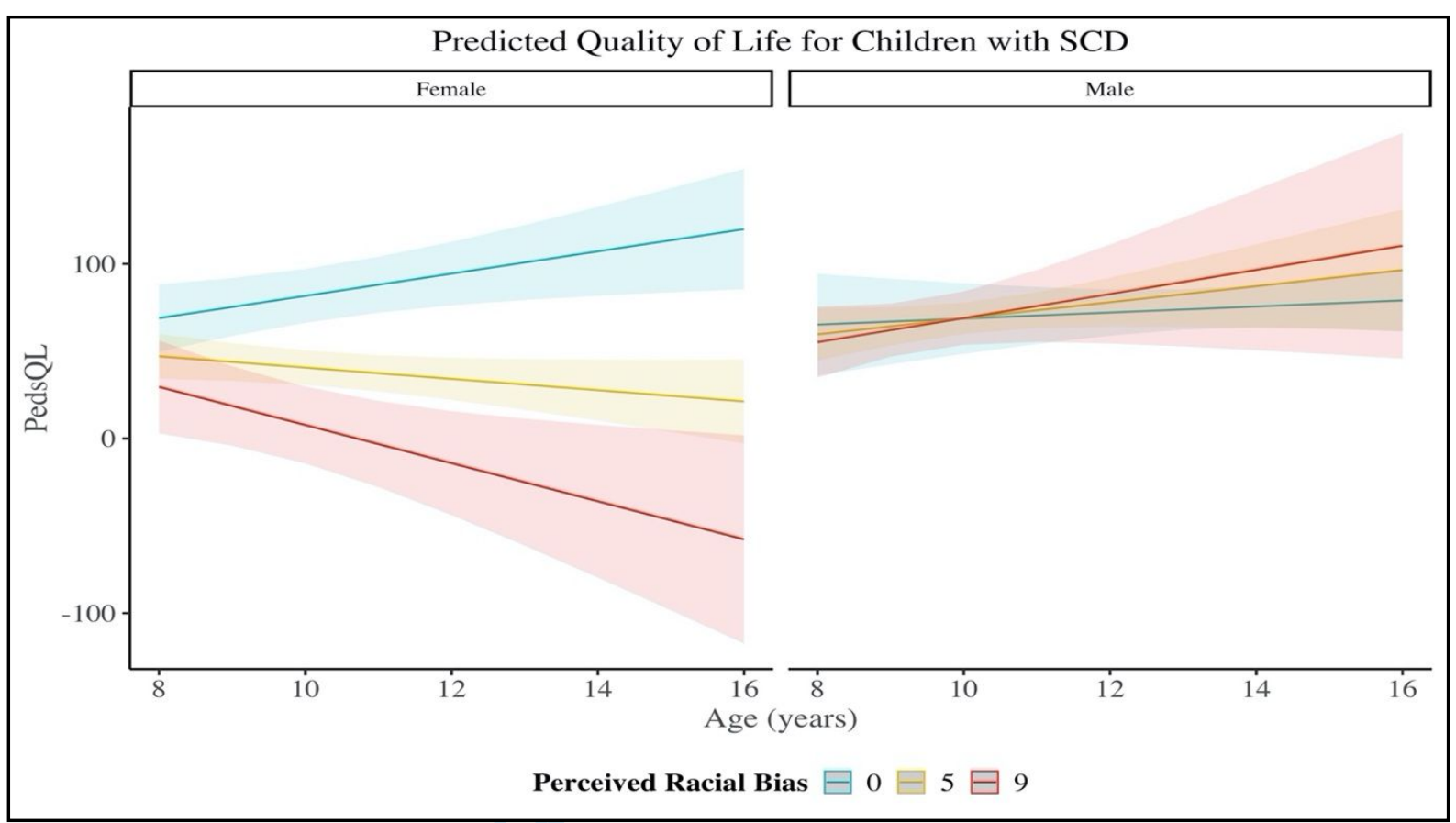

Figure 1. Predicted quality of life as a function of age and perceived racial bias at low, medium, and high levels. Shared areas indicate the $95 \%$ Confidence Intervals. PedsQL $=$ Pediatric Quality of Life Inventory Sickle Cell Disease Module. 